\title{
$\mathrm{B} 03$
}

\section{A 3D Conductivity Model of the Isle of Wight, UK, from Airborne EM Data}

\author{
J.C. White* (British Geological Survey) \& D. Beamish (British Geological \\ Survey)
}

\section{SUMMARY}

This study reports the first airborne electromagnetic (AEM) survey in southern England. An airborne geophysical survey incorporating magnetic, radiometric and electromagnetic observations was carried out in 2007 over a $36 \times 22 \mathrm{~km}$ area incorporating the Isle of Wight. The island is of significant geological interest due to the nature of the reactivated Variscan thrust faulting causing near vertical bedding along a central monocline. Of primary interest to this study was a first chance to deploy AEM over a significant chalk deposit and to assess the accuracy and resolution of the final 3D models in regions of significantly dipping, but well mapped, sedimentary beds. The results of multi-layer inversion are displayed across a 3D conductivity volume. The conductive Gault clay/mudstone is highly resolved against the more resistive Upper Greensand and Chalk and provides a detailed mapping of the concealed geological structure. 


\section{Introduction}

The Isle of Wight is England's largest island; situated off the south coast of Hampshire it offers a diverse range of geology for an area of its size $\left(380 \mathrm{~km}^{2}\right)$. Between September and October 2008 the island was surveyed as part of the High Resolution Airborne Resource and Environment Surveys (HiRES) program. The primary aim of the survey was to determine the geophysical responses of specific geology, characteristic of much of southern England, in relation to geologic map revision. The data were acquired with the Joint AirborneGeoscience Capability (JAC) 'three-in-one' measurement system which comprises magnetic, radiometric and active electromagnetic sensors mounted on a DeHavilland Twin-Otter. The airborne geophysical systems are described by Leväniemi et al. (2009). The full survey area covered a total on- and off-shore area of $36 \times 22 \mathrm{~km}$ which was investigated with flight lines spaced at $200 \mathrm{~m}$ in a N-S direction, orthogonal to the major structural trends of the region. A nominal survey altitude of $56 \mathrm{~m}$ was adopted, but over the built environment a regulatory flight altitude of $240 \mathrm{~m}$ was required. The survey obtained over 4,500 line $\mathrm{km}$ of data and provided the first airborne EM (AEM) survey undertaken across southern England.

\section{Geology}

The geology of the Isle of Wight can be fairly evenly divided into a northern zone of tertiary sands, clays and limestones and a southern region of Cretaceous strata; divided by the eastwest trending chalk beds of the late-Cretaceous (Figure 1). The island is of significant geological interest due to the nature of the reactivated Variscan thrust faulting causing near vertical bedding along a central monocline. Of primary interest to this study was a first chance to deploy AEM over a significant chalk deposit and to assess the accuracy and resolution of the final 3D models in regions of significantly dipping, but well mapped, sedimentary beds. Since the lithologies under investigation are repeated extensively on the mainland, the project served as a first opportunity to report on the signatures expected across a significant area of southern England.

\section{Conductivity models}

The four-component EM data (912, 3005, 11962 and $24510 \mathrm{~Hz}$ ) from vertical coplanar coils were recorded and subjected to the leveling procedures described by Leväniemi et al. (2009). Initially the EM coupling ratios were used to determine half-space apparent conductivity and apparent depth maps of the entire island in order to isolate regions of interest and to confirm that the levelling procedures had worked adequately. The mapped apparent conductivities display excellent correlation with the existing geological maps and the high frequency component can be used to assess the extent of the thicker superficial deposits.

Various multi-layer inversions have been used to provide 1D conductivity models. The models are stitched together and used in a number of 3D visualisation packages. In the first instance, 1D Occam inversions were undertaken to determine the broad resolution of the data and the continuity of the subsurface features. Initial model explorations are also required to assess the sea/land conductivity behaviour and the issue of high-fly zones (holes in the model data set) together with the influence of cultural noise on the data and resulting models.

The layered inversion procedure used here is the one-dimensional inversion code developed at the HydroGeophysics Group of the University of Aarhus, Denmark (Siemon et al., 2009). The procedures offer the opportunity for a laterally constrained inversion. From the initial investigations, a 7 layer inversion incorporating all four in-phase and quadrature components was performed with no constraints on the vertical position of the boundaries. The thicknesses of the layers remained unconstrained and the model is divided into sections of 10 soundings for the lateral continuity constraint. The horizontal constraint on resistivity is applied only

Near Surface $2009-15^{\text {th }}$ European Meeting of Environmental and Engineering Geophysics Dublin, Ireland, 7 - 9 September 2009 
lightly (a standard deviation of 1.8) and the models were not forced to be continuous between sections but each new section starts with the final model from the previous section.

As with any geophysical work in highly urbanised regions the EM/conductivity mapping of the Isle of Wight presented significant problems due to cultural disturbances. This was due to the necessary increase in flight altitude over the major built-up areas causing erroneous results in the mapping of conductivity and in the generation of the 3D subsurface model. Regions with an altitude over $125 \mathrm{~m}$ were blanked in the coupling ratio database which caused appreciable problems in the 3D volumetric interpolation of the final gridded models. These problems require a prior knowledge of the high-fly zones in order to avoid invalid conclusions.

\section{Conductivity model results}

Two rectilinear inshore areas (Figure 1) have been chosen to display the conductivity results obtained. In each case, slices from the 3D volumetric conductivity model are used to illustrate the relationships between the geological units and the distribution of subsurface conductivity. The 3D distribution is draped below a transparent topographic surface (vertically exaggerated). The half-space conductivity model at $3 \mathrm{kHz}$ is used as a base horizontal slice to aid location and to allow a comparison of half-space and multi-layer models. The conductivity slices extend to a depth of $100 \mathrm{~m}$.

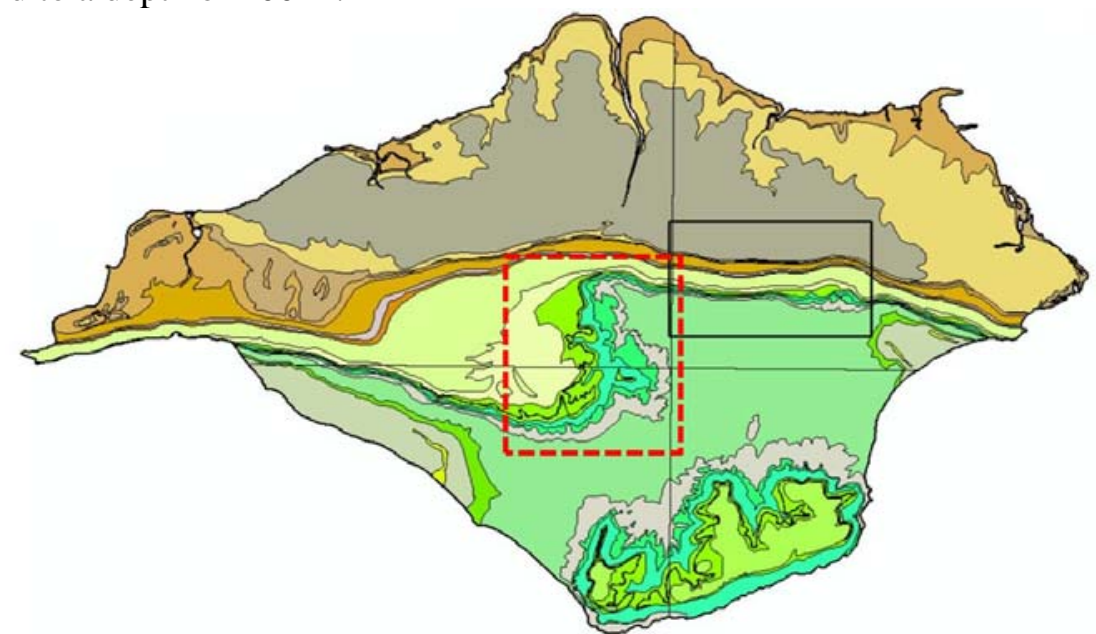

Figure 1. The bedrock geology of the Isle of Wight with the $7 \times 5 \mathrm{~km}$ (black rectangle) and the $6 \times 7$ $\mathrm{km}$ (red rectangle) regions of interest shown.

The first significant conclusion concerns the response of the chalk beds; these produce a well constrained resistive signature. This allows accurate mapping between the Lewes Nodular Chalk formation and the Lambeth Group clays and sands to the north. The resistive response from the chalk was expected from general background knowledge but the well mapped edges are a noteworthy discovery. Figure 2 shows $5 \mathrm{~N}-\mathrm{S}$ trending slices from the 3D model across the first $7 \times 5 \mathrm{~km}$ area. The section is centred across the central monocline to the ESE of Newport. This region contains thin, near-vertical Cretaceous beds alongside tertiary sediments and the chalk (labelled X), can be seen to be well defined at surface and at depth. Attention is also drawn to the conductive Gault unit (labelled Y) which in the zone of interest is only approximately $50 \mathrm{~m}$ wide at outcrop. Due to the footprint of the airborne EM data the resolution of thin vertical beds is generally poor, yet the Gault can be mapped both laterally and with depth. 


\section{Near Surface}

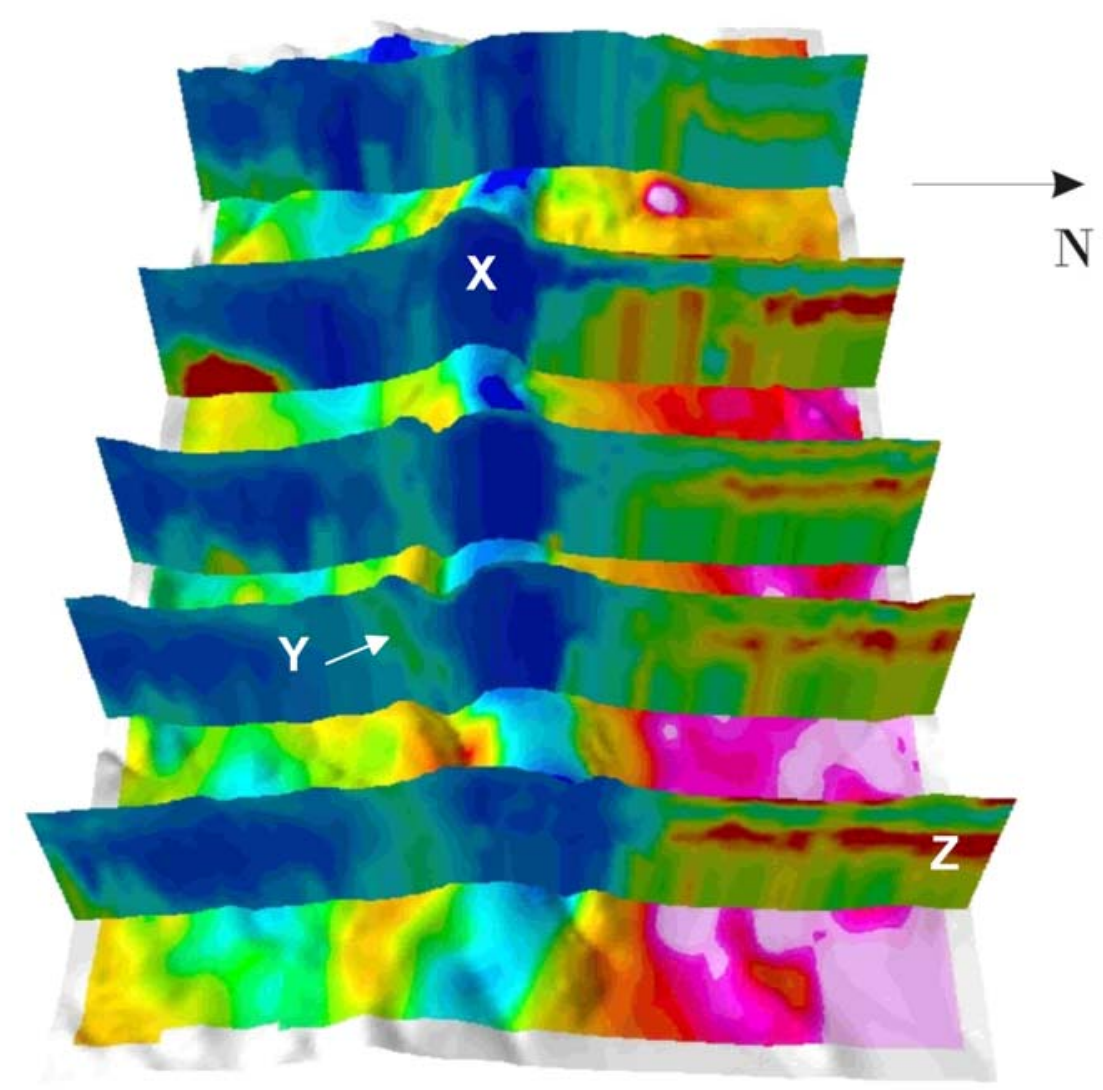

Figure 2. Area $1(7 \times 5 \mathrm{~km})$. Slices from the 3D conductivity model with the apparent conductivity map derived from the $3005 \mathrm{~Hz}$ data used as a horizontal base map. The resistive chalk (X) is continuous across the region and the dipping Gault unit $(\mathrm{Y})$ can also be traced between slices. To the north, highly conductive zones $(\mathrm{Z})$ are seen in the subsurface.

The primary conductor identified in the southern area of Isle of Wight is the Gault clay/mudstone of the Early Cretaceous. This is prominent at outcrop yet can be traced as a distinct unit under the more resistive Early Cretaceous Upper Greensand and Late Cretaceous Chalk formations. In regions where the bedding is significantly non-vertical this allows an accurate estimation of the local strike and dip of the boundaries.

The second area considered (see Fig. 1) is obtained across a $6 \times 7 \mathrm{~km}$ area over the complex relay ramp at the centre of the Isle of Wight monocline. Figure 3a shows slices from the $3 \bar{D}$ conductivity model with the $3 \mathrm{kHz}$ apparent resistivity map and the Gault unit, dipping away to the north-west, is characterised by distinct top and bottom surfaces. Figure 3b shows a 75 $\mathrm{mS} / \mathrm{m}$ isovolume that has captured the Gault unit (this is viewed from the opposite direction to (a)) with the surface distribution of Gault overlain to aid understanding. The clarity of the unit highlights the resolution available from the EM data set. The significant dip seen on these beds must continue to the north as local boreholes fail to intercept the Gault at depths up to $600 \mathrm{~m}$ less than $10 \mathrm{~km}$ away. 


\section{Near Surface}

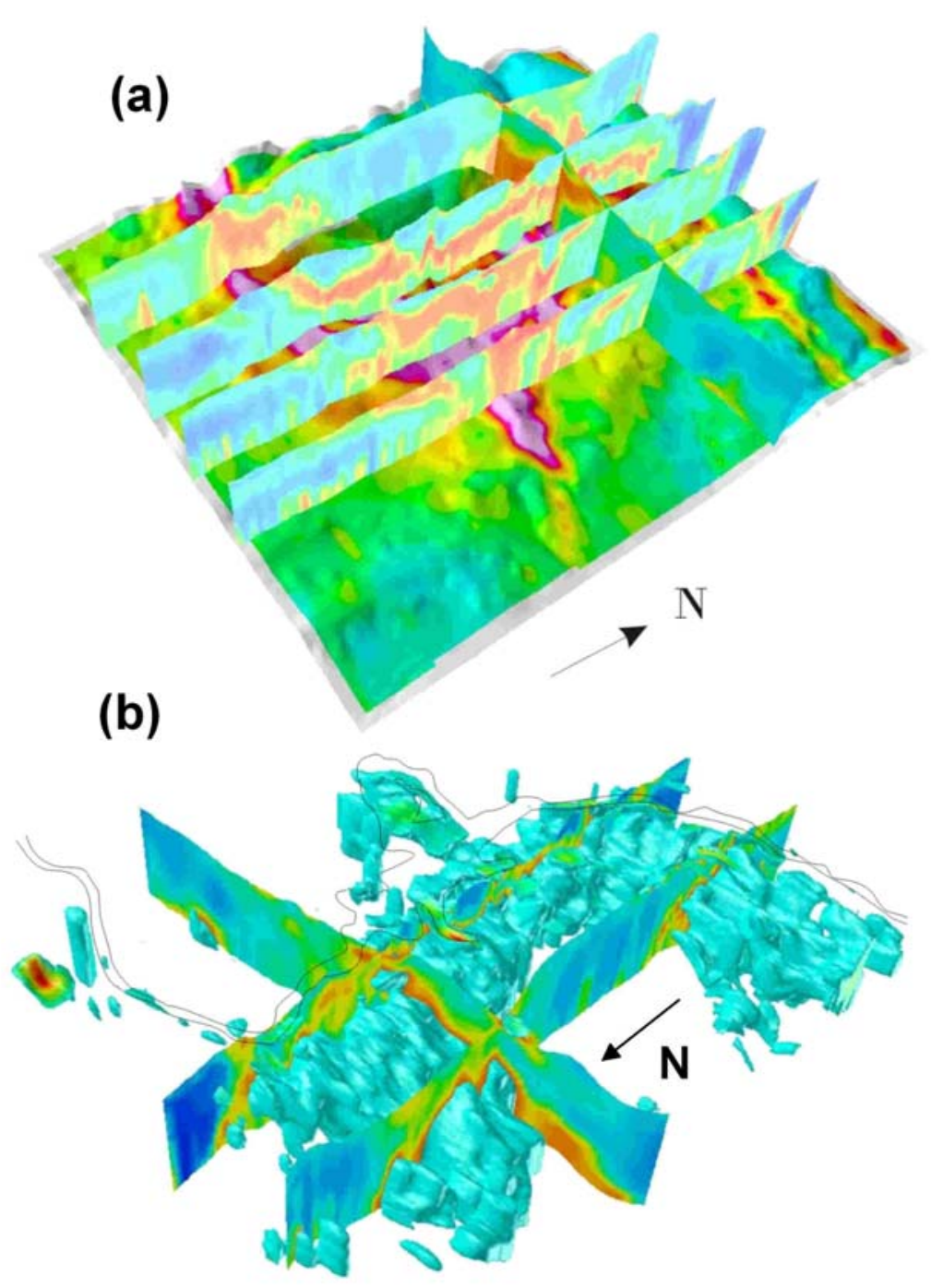

Figure 3. Area $2(6 \times 7 \mathrm{~km})$. Slices from the 3D conductivity model. (a) 2D slices from the 3D conductivity model with the $3 \mathrm{kHz}$ apparent conductivity displayed as the base map. The highly conductive Gault layer can be tracked across the model and displays excellent continuity with the outcrop. (b) an $75 \mathrm{mS} / \mathrm{m}$ isovolume highlighting the subsurface continuity of the Gault bed with the surface exposure overlain to aid understanding.

\section{Summary}

This study reports the first AEM survey across southern England. The Isle of Wight survey demonstrates the capability of airborne EM data in relation to concealed subsurface mapping of some of the major structural units of southern England.

\section{References}

Leväniemi, H., Beamish, D., Hautaniemi, H., Kurimo, M., Suppala, I., Vironmäki, J., Cuss, R.J., Lahti, M. and Tartaras, E. [2009] The JAC airborne EM system AEM-05. Journal of Applied Geophysics, 67, 219-233.

Siemon, B, Auken, E. and Christiansen, A.V., 2009. Laterally constrained inversion of helicopter-borne frequency-domain electromagnetic data. Journal of Applied Geophysics, 67, 219-233.

Near Surface $2009-15^{\text {th }}$ European Meeting of Environmental and Engineering Geophysics Dublin, Ireland, 7 - 9 September 2009 